\title{
Impact of self-management education on CD4 and health status of HIV/AIDS patients in semi-rural KwaZulu-Natal, South Africa
}

\author{
Folorunso D. Omisakin ${ }^{* 1}$, Busisiwe P. Ncama ${ }^{2}$, Adewumi S. Igbinlade ${ }^{3}$, Emmanuel O. Ayandiran ${ }^{4}$ \\ ${ }^{1}$ Faculty of Nursing, College of Health Sciences, Niger Delta University, Bayelsa State, Nigeria \\ ${ }^{2}$ School of Nursing, Howard College, University of KwaZulu-Natal, Durban, South Africa \\ ${ }^{3}$ School of Health Sciences, National Open University of Nigeria, Victoria Island, Lagos, Nigeria \\ ${ }^{4}$ Department of Nursing, College of Health Sciences, Obafemi Awolowo University, Ile-Ife, Nigeria
}

Received: March 15, 2015

DOI: $10.5430 /$ jnep.v5n12p25
Accepted: June 28, 2015

Online Published: September 10, 2015

\begin{abstract}
This paper reports on the impact of an intervention to encourage self-management of treatment upon CD4 ratios and health status of HIV/AIDS patients: a quasi experimental study in a semi-rural area in KwaZulu-Natal province in South Africa. Participants were a purposive sample of 88 HIV/AIDS patients. Participant's CD4 cell count results were retrieved from the clinic records and a questionnaire was administered pre- and post-intervention after twelve weeks. Paired Samples Test results reveal a statistically significant difference between the mean CD4 counts pre- and post-intervention for both groups. However, the differences between means for both groups deviated from one another significantly. The intervention group shows a higher mean difference. For the intervention group the difference between means was -178.09 , while -72.29 was the difference between means for the control group. Post-intervention results showed that the intervention and control groups are statistically significantly different in terms of CD4 count mean scores $(t=3.741 ; \mathrm{df}=80 ; p=.000<.05)$; and their mean scores on physical functioning $(t=3.900 ; \mathrm{df}=79 ; p=$ $.000<.05)$, vitality $(t=3.285 ; \mathrm{df}=79 ; p=.002<.05)$ and general health $(t=2.107 ; \mathrm{df}=79 ; p=.039<.05)$, physical health $(p=$ $.001<.05)$ and role limitation due to emotional problem $(p=.007<.05)$. The study demonstrated that self-management education impact positively and significantly on the mean CD4 cell counts and health status of HIV/AIDS patients. The findings suggests that combining self-management education with highly active antiretroviral therapy may improve health care of HIV/AIDS patients in resource limited rural setting and most likely in other settings.
\end{abstract}

Key Words: HIV/AIDS patients, Self-management education, Quality of life, CD4 cell counts, Nursing care, Semi-rural South Africa, Short Form 36

\section{INTRODUCTION}

The key feature of treatment of chronic illnesses is "self management"; hence as HIV/AIDS becomes definable more as a chronic illness due to more and more people on Antiretroviral therapy (ART) and needing long term treatment in order to recover and maintain their health, self-management of treatment - will need to be promoted. This study affirms the utility of self-management initiatives in improving the health of HIV/AIDS patients on ART as measured respectively by CD4 counts and self-reported health status.

\footnotetext{
* Correspondence: Folorunso D. Omisakin; Email: omifod@yahoo.co.uk; Address: Faculty of Nursing, College of Health Sciences, Niger Delta University, Bayelsa State, Nigeria.
} 
There is continuous pressure on how to locate more resources on treatment programs for HIV/AIDS patients. ${ }^{[1]}$ While many studies have examined the effectiveness of selfmanagement education interventions, only a few studies have investigated the impact of self-management on CD4 cell counts and health issues among HIV/AIDS patients in resource limited semi-rural KwaZulu-Natal, South Africa.

Economic and clinical evaluations of HIV/AIDS interventions have focused on simple clinical outcomes such as mortality or averted cases of HIV changes in patient's life expectancy and in health status. ${ }^{[2]}$ Recently, assessments of the effectiveness of various interventions extend beyond the traditional indices of symptom reduction and prevention of mortality, to encompass changes in the overall quality of individuals' lives. ${ }^{[3-5]}$ Research that examines the effect of self-management interventions on CD4 and health status is likely to obtain a more complete understanding of the relationship between this intervention and health outcomes in HIV/AIDS patients. Health status of HIV/AIDS patients also depend on socioeconomic and psychological factors and quality of healthcare services thus indicating a need to compile socioeconomic and psychological variables for (HIV/AIDS patients) for improving their health status and quality of life. ${ }^{[6]}$ Self management for chronic diseases is a well established principle. ${ }^{[7-9]}$ However, there is little information available to those who are interested in implementing or purchasing such programs as to its effect on health amongst patients taking antiretroviral therapy. CD4 cell count measurement is means used by the study to measure effect on health of HIV/AIDS patients to help them decide how to design or structure their programs.

This paper describes a project to apply self-management education which was conducted in an ART program in a semirural location in KwaZulu-Natal province of South Africa. The questions asked were: (1) Is there a significant difference between the study groups in terms of demographic variables, CD4 cell counts and health status before and after implementation of self-management education? (2) Are differences between CD4 counts mean scores between groups deviate from one another accidental or is a function of intervention?

\section{Background}

Generally, scholars agreed that the term self-management can apply to health promotion activities as well as to those related to acute or chronic illness. ${ }^{[10]}$ It consists of: (i) recognition of a change in sign or symptoms in relation to the illness; (ii) the change evaluation; (iii) implementation of selected treatment strategy; and (iv) evaluation of the effectiveness of treatment. ${ }^{[11]}$ It can be viewed as an interpersonal process involving the personal care of individuals as they experience illness within a therapeutic context i.e., an individual's ability to manage the symptoms, treatment, physical and psychosocial consequences and life style changes inherent in living with a chronic condition. ${ }^{[12]}$ Self-management education aims at helping patients to maintain, mainly by their own efforts, the best possible health. It includes the provision of information, self-monitoring, regular medical review and the provision of a written self-management plan.

Self-management has emerged as a critical component of care for HIV/AIDS patients. Many HIV/AIDS patients find it challenging to attend to daily tasks of living, participate in moderate to vigorous physical activities, or have sufficient energy or vitality to engage in social life while managing HIV/AIDS, ${ }^{[13]}$ they are vulnerable to multiple health problems and many live in poverty, furthering the decrease in their health-related quality of life. ${ }^{[14]}$ Few reports from sub-Saharan Africa are known to include the concept of selfmanagement among PLWHA with the advent of highly active antiretroviral therapy (HAART).

Quality of life of HIV/AIDS patients was conceived to encompass four interrelated dimensions: the physical health; psychological health; social health; and the environmental factors. ${ }^{[15]}$ Quality of life of HIV/AIDS patients is complex and is determined by multiple factors such as: poverty, stigma, discrimination, and lack of treatment combined with family life, work, and social activities. ${ }^{[16]}$ Quality of life relates to individuals' perception of their position in life in the context of the culture and value systems and how it affects their set goals, expectations, standards and concerns", ${ }^{[17]}$ while health-related quality of life refers to how well people can perform daily activities and how good they feel about their lives. ${ }^{[18]}$ Health-related quality of life is important to HIV/AIDS patients because the effects of the disease influence every aspect of their daily life. ${ }^{[19]}$ In order to have effective self-management intervention for HIV/AIDS patients, their health-related quality of life should be addressed as well the broader determinants of health. Health-related quality of life can be seen as the health dimension of quality of life that constitutes a subjective evaluation of various aspects of one's life. ${ }^{[20]}$ Studies have shown that the assessment of quality of life does provide information on the life experiences of people with acute illnesses, and may be of particular importance to people who suffer from chronic diseases such as HIV/AIDS.

Determining the inter-relationships between biological markers of HIV/AIDS patients and interventions are complex and demand the use of elaborate data and statistical techniques to extract information that can be utilized for policy formulation. In particular, the impact of self-management education 
on outcomes such as patients' CD4 cell counts, and effects of higher CD4 cell count on quality of life indicators merit investigations in a comprehensive framework.

\section{METHOD}

\subsection{Aim}

The aim of this study was to measure the impact of selfmanagement education program on health status of ART patients by use of two sets of indicators - CD4 cell counts and health status, in an ART program in semi-rural, KwaZuluNatal province of South Africa as a context for evaluating self-management education interventions.

\subsection{Design}

The study employed quasi-experimental design, HIV/AIDS patients were divided into intervention and control group (one received self-management education program; other did not). We retrieved CD4 cell counts results from clinic records using a document review checklist, and administered Short Form 36 (SF-36) questionnaire to HIV/AIDS patients preand post self-management education. SF-36 questionnaire, focuses on the respondent's self-report of experiences, feelings, beliefs and convictions about their health-related quality of life, consists of eight scales namely: (a) physical functioning (PF); (b) role limitations due to physical health (RP); (c) role limitations due to emotional problems (RE); (d) bodily pain (BP); (e) mental health (MH); (f) social functioning; (g) vitality (VT); and (h) general health $(\mathrm{GH})$ perceptions. The content validity of the SF-36 questionnaire is confirmed by systematic comparisons that indicate that this questionnaire includes eight of the most frequently represented health concepts in the measurement of health-related quality of life. ${ }^{[21]}$ "Pearson bivariate correlation showed moderate correlations between the SF-36 scales. Internal reliability was estimated using Cronbach's- $\alpha$. Cronbach's- $\alpha$ was greater than 0.70 for six out of eight multi-item scales, with value ranging from 0.6298 to 0.8860 for all scales, with 0.6500 for VT and 0.6298 for $\mathrm{GH}$ indicating good internal reliability of SF36". ${ }^{[22]}$ SF-36 Questionnaire is considered to be one of the best instruments, for measuring the health status of patients with acute and chronic diseases in clinical practice in various situations and under different circumstances.

\subsection{A description of the self-Management intervention} The HIV/AIDS Self-Management Education Programme (HASMEP) was guided by HIV/AIDS Self-Management Education Model developed by the first author in 2010 in response to the self-management education needs. ${ }^{\text {[23] }}$ HASMEP was designed to encompass both individual and group engagements working towards the empowerment of HIV/AIDS patients. The programme aims to enable
HIV/AIDS patients use self-management strategies such as medication and symptom self-management; and sourcing for help, and dealing with the emotional consequences of living with HIV/AIDS. ${ }^{[3]}$ It consists of fourteen bi-weekly sessions (120 to 150 minutes) and emphasizes participants' central role and responsibility in managing their illness. The sessions consisted of supervised dialogue, physical activity and education. The main goal was for HIV/AIDS patients to gain knowledge and skills to self-manage and improve their health and social well-being. Acquisition of knowledge and skills was to be driven by behavior change goals, not by a fixed curriculum. However, the topics for the sessions include: goal setting, increasing emotional capacity, increasing knowledge of HIV/AIDS, positive living and self-management, active antiretroviral therapy, nutrition, water, control of infection, hygiene, physical exercise, self-management strategies, networking and communication. Self-management educational material used as homework was included. These self-management techniques are facilitated through weekly action planning and feedback on progress, modeling of self-management behavior and problem-solving strategies, understanding of physiological symptoms, and social persuasion through group support and guidance for individual self-management efforts. ${ }^{[24]}$ A self-management handbook, based on findings from the needs assessment, ${ }^{[25]}$ was distributed to members of the Intervention Group to be used as a reference source for the material covered in the sessions. They received this book at the first session of the program. The program comprises a professional leader'(first author) and peer leaders'(HIV/AIDS patients), acting as role models for the participants in the study.

Current health problems and the reasons they occurred were focused upon, recorded, and assessed continually throughout the program. Treatment goals and objectives were specified by the participants and recorded. Each HIV/AIDS patient's expectations of the costs and benefits of the changes they were making and confidence in their ability to achieve their goals were measured at each visit. With regard to compliance, the leaders recorded after each session on group member's adherence to specified time limits, or utilization of different training techniques from those specified in the protocol. In addition, they recorded preparation time, travel time, time spent on the session, and activities resulting from the session. They reported on patient attendance and adherence at group level. Absent participants were phoned by the first author to ask about the reasons for their absence. After completing the program, both leaders and PLWHA reported on the overall performance (i.e., HIV/AIDS patient's efforts during the sessions) with regard to homework assignments (e.g., did group members achieve the weekly targets?). 


\subsection{Participants}

The participants were a purposive sample of 88 adults HIV/AIDS patients recruited from a clinic in a semi-rural area in KwaZulu-Natal province of South Africa. This clinic, an antiretroviral roll out centre was selected because high numbers of HIV/AIDS patients were receiving treatment at the facility at the time the study was proposed. To be eligible for this study, the participant had to meet the following criteria: over 18 years of age, be HIV-positive, in WHO stage 2 or more of HIV/ AIDS, be on HAART for at least 3 months prior to the study, not be participant in any other similar program for the prior 3 months, received medical approval, consented to participate, and is able to complete the study instrument in English or isiZulu.

\subsection{Data collection}

Data on CD4 cell counts were obtained from the Medical Records Department of the clinic. The investigators used a document review checklist to retrieve data on CD4 cell counts pre- and post-intervention from participant's clinic records. In addition, SF-36 was self-administered to assess health-related quality of life of participants. Participant's privacy was ensured throughout by having the interviews conducted in a private room. Participants indicated as applicable to themselves, each item in SF-36 questionnaire. Of 88 participants, 81 participants completed the SF-36 questionnaire post-intervention.

\subsection{Ethical considerations}

Ethics committees of the University of KwaZulu-Natal and the Department of Health of the province approved the study before the commencement of data collection. Participants received an information document - and details of the study were verbally explained. Written informed consent was obtained from all participants. Participant's health and wellbeing were regarded as paramount throughout, and participation was voluntary. Confidentiality and anonymity were maintained throughout the period of study. Participants also received 30 South African Rand (R30) as reimbursement for their travel expenses and for the completion of the baseline questionnaires.

\subsection{Data analysis}

This paper analyses data from an ongoing longitudinal study in the semi-rural KwaZulu-Natal Province of South Africa, where 88 patients were observed at two points in time with a twelve week interval. Responses to the questionnaires were transcribed, coded, and entered into Statistical Package for Social Sciences (SPSS) Windows 15.0 for data analysis. The standard method for scoring SF-36 was used in calculating the mean scores for the eight domains. ${ }^{[21]}$

One-Sample kolmogorov-Smirnov Test was performed to check for normality in the data. The test revealed the normal and skewed data requiring different tools for analysis. Independent Samples Test or Mann-Whitney Tests were used depending on whether the data is normally distributed or skewed. ANOVA was used to determine between-subject effects.

\section{RESUlts}

The age of these participants ranged from 18-60 years. The mean age for participants in the intervention group was 34.95 while the mean age for participants in the comparison group was 31.75 (see Table 1). The two groups are not statistically significantly different in terms of their mean scores on age $(t$ $=1.394 ; \mathrm{df}=86 ; p=.167$ ) (see Table 2). There were more females than males in both groups in this study. The groups are also similar in terms of gender composition (see Table $3)$.

Table 1. The Intervention and comparisons groups' ages

\begin{tabular}{lll}
\hline Groups & Mean & Standard Deviation \\
\hline Intervention & 34.95 & 11.35 \\
Control & 31.75 & 10.18 \\
\hline
\end{tabular}

Table 2. Independent samples test results

\begin{tabular}{lllll}
\hline & \multicolumn{4}{l}{$\boldsymbol{t}$-test for Equality of Means } \\
\cline { 2 - 5 } & $\boldsymbol{T}$ & $\mathbf{D f}$ & Sig (2-tailed) & Mean Difference \\
\hline Age Equal variances assumed & 1.394 & 86 & .167 & 3.205 \\
Equal variances not assumed & 1.394 & 84.990 & .167 & 3.205 \\
\hline
\end{tabular}

Table 3. The intervention and comparisons groups' gender

\begin{tabular}{llll}
\hline \multirow{2}{*}{ Groups } & \multicolumn{2}{l}{ Gender } & \multirow{2}{*}{ Total } \\
\cline { 2 - 3 } & Male & Female & \\
\hline Intervention & $10(20.93 \%)$ & $34(79.07 \%)$ & $44(100 \%)$ \\
Control & $11(23.26 \%)$ & $33(76.74 \%)$ & $44(100 \%)$ \\
\hline
\end{tabular}

At baseline (pre-intervention) there was no statistically significant difference between groups in terms of HRQOL. The $p$ values are greater than .05. (see Tables 4 and 5). Also, the two groups were not statistically significantly different in terms of their CD4 count mean scores $(t=.385 ; \mathrm{df}=86 ; p$ $=.702>.05)($ see Table 6$)$. 
Table 4. Independent samples test result

\begin{tabular}{llllll}
\hline & & \multicolumn{4}{l}{ t-test for Equality of Means } \\
\cline { 3 - 6 } & & $\boldsymbol{T}$ & Df & Sig (2-tailed) & Mean Difference \\
\hline \multirow{2}{*}{ VT } & Equal variances assumed & -1.163 & 86 & .248 & -4.20455 \\
& Equal variances not assumed & -1.163 & 83.288 & .248 & -4.20455 \\
\multirow{2}{*}{ BP } & Equal variances assumed & -.802 & 86 & .425 & -4.26136 \\
& Equal variances not assumed & -.802 & 85.977 & .425 & -4.26136 \\
\multirow{2}{*}{ GH } & Equal variances assumed & .635 & 86 & .527 & 2.46212 \\
& Equal variances not assumed & .635 & 83.832 & .527 & 2.46212 \\
\hline
\end{tabular}

Table 5. Mann-Whitney test results

\begin{tabular}{llllll}
\hline & PF & RP & RE & MH & SF \\
\hline Mann-Whitney U & 953.000 & 928.000 & 911.000 & 943.000 & 918.500 \\
Wilcoxon W & 1943.000 & 1918.000 & 1901.000 & 1933.000 & 1908.500 \\
Z & -.126 & -.347 & -.492 & -.211 & -.424 \\
Asymp.sig. (2-tailed) & .900 & .729 & .623 & .833 & .672 \\
\hline
\end{tabular}

Table 6. Independent samples test results pre-intervention

\begin{tabular}{llllll}
\hline & \multicolumn{4}{l}{$\boldsymbol{t}$-test for Equality of Means } & \\
\cline { 3 - 6 } & & $\boldsymbol{T}$ & Df & Sig (2-tailed) & Mean Difference \\
\hline \multirow{2}{*}{ CD4 before } & Equal variances assumed & .385 & 86 & .702 & 9.864 \\
& Equal variances not assumed & .385 & 81.353 & .702 & 9.864 \\
\hline
\end{tabular}

Post-intervention results showed that the two groups are sta- The two groups are not statistically significantly different in tistically significantly different in terms of their mean scores terms of their mean scores on mental health $(t=1.422 ; \mathrm{df}=$ on physical functioning $(t=3.900 ; \mathrm{df}=79 ; p=.000<.05), 79 ; p=.158>.05)$, bodily pain $(t=-.138 ; \mathrm{df}=79 ; p=.891$ vitality $(t=3.285 ; \mathrm{df}=79 ; p=.002<.05)$ and general health $>.05)$ and social functioning $(p=.249>.05)($ see Table 7$)$. $(t=2.107 ; \mathrm{df}=79 ; p=.039<.05)$, physical health $(p=.001<\quad$ Post-intervention the two groups are statistically significantly $.05)$ and role limitation due to emotional problem $(p=.007$ different in terms of their CD4 count mean scores $(t=3.741$; $<.05$ ) (see Table 7) but the intervention group scored better. $\mathrm{df}=80 ; p=.000<.05$ ) (see Table 8 ).

Table 7. Independent samples test results

\begin{tabular}{|c|c|c|c|c|c|}
\hline & & \multicolumn{4}{|c|}{ t-test for Equality of Means } \\
\hline & & $T$ & Df & Sig (2-tailed) & Mean Difference \\
\hline \multirow{2}{*}{ PF } & Equal variances assumed & 3.900 & 79 & .000 & 23.60061 \\
\hline & Equal variances not assumed & 3.895 & 77.715 & .000 & 23.60061 \\
\hline \multirow{2}{*}{ VT } & Equal variances assumed & 3.285 & 79 & .002 & 10.73476 \\
\hline & Equal variances not assumed & 3.277 & 75.827 & .002 & 10.73476 \\
\hline \multirow{2}{*}{$\mathrm{MH}$} & Equal variances assumed & 1.422 & 79 & .159 & 5.20244 \\
\hline & Equal variances not assumed & 1.427 & 74.302 & .158 & 5.20244 \\
\hline \multirow{2}{*}{$\mathrm{BP}$} & Equal variances assumed & -.138 & 79 & .890 & -.71189 \\
\hline & Equal variances not assumed & -.138 & 72.642 & .891 & -.71189 \\
\hline \multirow{2}{*}{ GH } & Equal variances assumed & 2.107 & 79 & .038 & 7.03506 \\
\hline & Equal variances not assumed & 2.104 & 77.454 & .039 & 7.03506 \\
\hline
\end{tabular}

Table 8. Independent samples test results post-intervention

\begin{tabular}{llllll}
\hline \multirow{2}{*}{ CD4 After } & \multicolumn{4}{l}{$\boldsymbol{t}$-test for Equality of Means } \\
\cline { 3 - 6 } & $\boldsymbol{T}$ & Df & Sig (2-tailed) & Mean Difference \\
\hline \multirow{2}{*}{ Equal variances assumed } & 3.741 & 80 & .000 & 110.657 \\
& Equal variances not assumed & 3.775 & 72.631 & .000 & 110.657 \\
\hline
\end{tabular}


A repeated measure of variance (ANOVA) was used to determine whether the differences between two or more mean deviate from one another significantly was accidental or is function of intervention. There was statistically significant in between-subject effects $(p=.026<.05)$ (see Table 9). Paired Samples $t$ Test results; shows that there was a statistically significant difference between the mean CD4 cell counts pre- and post-intervention for both groups and the differences between means for both groups deviated from one another significantly. The intervention group shows a higher mean difference. For the intervention group the difference between means was -178.09 , while -72.29 was the difference between means for the control group (see Tables 10 and 11).

Table 9. Tests of between-subjects effects (Transformed Variable: Average)

\begin{tabular}{llllll}
\hline Source & Type iii Sum of Squares & Df & Mean Square & F & Sig. \\
\hline Intercept & 9447056.652 & 1 & 9447056.652 & 374.735 & .000 \\
Group & 130617.043 & 1 & 130617.043 & 5.181 & .026 \\
Error & 2016797.152 & 80 & 25209.964 & & \\
\hline
\end{tabular}

Table 10. Intervention group paired samples statistics

\begin{tabular}{llllll}
\hline & Mean & N & Std. Deviation & Std. error Mean \\
\hline \multirow{2}{*}{ Pair 1 } & CD4 Before & 187.27 & 44 & 113.053 & 17.444 \\
& CD4 After & 365.36 & 41 & 155.708 & 24.026 \\
\hline
\end{tabular}

Table 11. Comparison group paired samples statistics

\begin{tabular}{llllll}
\hline & & Mean & N & Std. Deviation & Std. error Mean \\
\hline \multirow{2}{*}{ Pair 1 } & CD4 Before & 177.41 & 44 & 94.442 & 14.933 \\
& CD4 After & 254.70 & 40 & 106.231 & 16.797 \\
\hline
\end{tabular}

Physical functioning refers to the extent to which the participants are able to perform vigorous activities such as running, lifting heavy objects, participating in strenuous sports, climbing several flights of stairs and walking more than a kilometer, it entails the performance of moderate activities such as bending, kneeling or stooping, bathing and dressing themselves.

\section{DISCUSSION}

In South Africa, the great preponderance of AIDS care and management occurs in the PLWHA's residence and settings that have established $\mathrm{CHBC}$ programmes with primary caregivers (kin) and secondary caregivers/Community health workers being involved, and this depends on whether ART programme is NOG/FBO or government owned.

Post-intervention measurements revealed a statistically significant improvement in domains of health-related quality of life of the participants. Most importantly, there is statistically significant difference between groups in terms of their mean scores for PF, VT, GH, RP and RE domains of health-related quality of life only, but no statistically significant difference between groups post-intervention in terms of mean scores for social functioning, mental health and bodily pain.

The findings indicated that not only did the health-related quality of life of PLWHA not deteriorate during the course of the study, but that it demonstrated progressive improvement in both groups, this is most likely due to the fact that both groups are on HAART. The mean CD4 cell counts increased over the period in both groups but the change in mean CD4 cell counts scores deviate significantly from each other with the intervention group having better score. The study demonstrated that self-management education impact positively and significantly on the mean CD4 cell counts and health-related quality of life of PLWHA. These findings are consistent with previous studies where it was reported that emotional and other forms of support received by patients for maintaining medication schedule enhanced the efficacy of ART and are useful explanatory variables in the models for CD4 cell counts and quality of life indices. ${ }^{[26,27]}$

The result indicated that the use of self-management education initiative is important for improving health status and quality of life of people living with HIV/AIDS most especially in resource limited rural communities. Healthcare infrastructure and emotional support are predictors of CD4 cell counts and quality of life indices of patients on antiretroviral treatment ${ }^{[6]}$ - these can further be enhanced with self-management education.

The fact that higher CD4 cell count associates with better quality of life suggests that CD4 cell counts are likely to be useful measure for PLWHAs' health status and well-being. 
The study shows that there is a direct positive relationship between CD4 cell counts and health-related quality of life among people living with HIV/AIDS post- self-management education intervention.

Pre-intervention measurement revealed that majority of the participants reported low levels of well being at the time of study even though were on ART as reflected by the low mean score for all eight domains of SF-36 (see Tables 12 and 13). It is evident that the participants have attained low scores in all eight domains with the lowest score on physical functioning. It is worth mentioning that the mean CD4 cell counts increased significantly in both groups and this could be explained by the fact that both groups are on highly active antiretroviral therapy. However, there was a significant difference in the mean CD4 cell count changes between the groups at the post-intervention assessment point. The fact that the intervention impacted positively on the mean CD4 cell count for the intervention group could be used to explain this differential. Higher CD4 cell count is associated with better quality of life, and suggests the CD4 cell counts are likely to be useful measurement for PLWHA's health status and well being. The study shows that there is a direct positive relationship between CD4 cell counts and health-related quality of life amongst PLWHA.

Health-related quality of life is increasingly acknowledged as a valid health indicator in many diseases. The study provides useful information on measures of effect of self-management education programs on CD4 cell counts and quality of life of PLWHA. It also provides background knowledge about CD4 cell counts as correlates of quality of life of PLWHA in a semi-rural KwaZulu-Natal province.

Table 12. Group statistics for normally distributed data

\begin{tabular}{llllll}
\hline \multicolumn{2}{l}{ Experimental group } & $\mathbf{N}$ & Mean & Std. Deviation & Std. Error Mean \\
\hline \multirow{2}{*}{ VT } & Intervention & 44 & 39.5455 & 15.35692 & 2.31514 \\
& Control & 44 & 43.7500 & 18.43042 & 2.77849 \\
BP & Intervention & 44 & 51.8182 & 24.72737 & 3.72779 \\
& Control & 44 & 56.0795 & 25.13567 & 3.78934 \\
GH & Intervention & 44 & 45.6439 & 19.60434 & 2.95547 \\
& Control & 44 & 43.1818 & 16.66887 & 2.51293 \\
\hline
\end{tabular}

Table 13. Ranks for skewed data (non-normally distributed data)

\begin{tabular}{lllll}
\hline Experimental group & & N & Mean Rank & Sum of Ranks \\
\hline \multirow{3}{*}{ PF } & Intervention & 44 & 44.84 & 1973.00 \\
& Control & 44 & 44.16 & 1943.00 \\
& Total & 88 & & 1918.00 \\
RP & Intervention & 44 & 43.59 & 1998.00 \\
& Control & 44 & 45.41 & 2014.50 \\
& Total & 88 & 45.78 & 1901.50 \\
RE & Intervention & 44 & 43.22 & 1933.00 \\
& Control & 44 & & 1983.00 \\
MH & Total & 88 & 43.93 & 1908.50 \\
& Intervention & 44 & 45.07 & 2007.50 \\
& Control & 44 & & \\
\end{tabular}

\section{Study limitations}

The sample size and the very small number of drop-outs could be considered the strengths of the study. The generalizability of these findings is supported by use of purposive sampling technique, but the selection criteria does not allow for sample across the stages of the disease. A limitation was the possible effect of a response bias noting that participants where those already known and the seven participants (3 from intervention and 4 from control group) who did not complete the questionnaire, were either deceased $(n=2)$ or were acutely ill when contacted $(n=5)$. However, while this may have slightly biased the responses, it is unlikely to have influenced the identification of health-related quality of life domains, which were broad and likely to be transferable to other PLWHA. 
A further limitation lies in the process of collecting CD4 cell counts data. Collecting CD4 cell counts data via clinic records provides the convenience, non-invasiveness, lowcost, and confidentiality but with threats of unreliability and invalidity. However, the client attendance register in the clinic records were reviewed, data collection was reliable and valid. Standard procedures were observed for all the tests done at the clinic within the period.

\section{Conclusion}

The study demonstrated the effect of self-management education intervention on the mean CD4 cell counts and quality of life of people living with HIV/AIDS. Also, useful information was provided on the association between CD4 and quality of life of people living with HIV/AIDS. A combination of self-management education with HAART will improve health care of PLWHA in resource limited rural and most likely in other settings. Quality of life is severely compromised in people living with HIV/AIDS.

\section{Conflicts of InTEREST Disclosure}

The authors declare that there is no conflict of interest.

\section{REFERENCES}

[1] Shiffman J. Donor funding priorities for communicable disease control in the developing world. Health Policy Plan. 2006; 21(6): 411 420. PMid:16984894 http://dx.doi.org/10.1093/heapol/cz 1028

[2] Robberstad B, Olsen J. The health related quality of life of people living with HIV/AIDS in Sub-Saharan Africa-a literature review and focus group study. Cost Effectiveness and Resource Allocation. 2010; 8: 5-11. PMid:20398367 http://dx.doi.org/10.1186/1478-7 547-8-5

[3] Lorig K, Holman H. Self-Management Education: History, Definition, Outcomes, and Mechanisms. Annals of Behavioral Medicine. 2003; 26: 1-7. PMid:12867348 http://dx.doi.org/10.1207/S 15324796ABM2601_01

[4] Jerant A, von Frederichs-Fitzwater M, Moore M. Patient's perceived barriers to active self-management of chronic conditions. Patient Education and Counseling. 2005; 57: 300-307. PMid:15893212 http://dx.doi.org/10.1016/j.pec.2004.08.004

[5] Wilde M, Garvin S. A concept analysis of self-monitoring. Journal of Advanced Nursing. 2007; 57: 339-350. PMid:17233653 http://dx.doi.org/10.1111/j.1365-2648.2006.04089.x

[6] Bhargava A, Booysen F. Healthcare infrastructure and emotional support are predictors of CD4 cell counts and quality of life indices of patients on antiretroviral treatment in Free State Province, South Africa. AIDS Care. 2010; 22(1): 1-9. PMid:20390475 http: //dx.doi.org/10.1080/09540120903012585

[7] Inouye J, Flannelly L, Flannelly K. The effectiveness of selfmanagement training for individuals with HIV/AIDS. Journal of Association of Nurses in AIDS Care. 2001; 12: 71-82. http: //dx.doi.org/10.1016/S1055-3290(06)60264-1

[8] Bodenheimer T, Wagner E, Grumbach K. Improving primary care for patients with chronic illness, The Journal of the American Medical Association. 2002; 288(14): 1775-1779. PMid:12365965 http://dx.doi.org/10.1001/jama.288.14.1775

[9] Coleman M, Newton K. Supporting Self-management in Patients with Chronic Illness. American Family Physician. 2005; 72: 1503 1510. PMid:16273817

[10] Wagner E, Davis C, Shaefer J, et al. survey of leading chronic disease management programs: Are they consistent with literature? Journal of Nursing Care Quality. 2002; 16: 67-80. http: //dx.doi.org/10.1097/00001786-200201000-00008

[11] Kralik D, Koch T, Price K, et al. Chronic illness self-management: Taking action to create order. Journal of Clinical Nursing. 2004;
13: 259-267. http://dx.doi.org/10.1046/j.1365-2702.20 $03.00826 . \mathrm{x}$

[12] Barlow J, Wright C, Sheasby J, et al. Selfmanagement approaches for people with chronic conditions: a review. Patient Educationand Counseling. 2002; 48: 177-187. http://dx.doi.org/10.1016/S 0738-3991 (02) 00032-0

[13] Vosvick M, Koopman C, Gore-Felton C, et al. Relationship of functional quality of life to strategies for coping with the stress of living with HIV/AIDS. Psychosomatics. 2003; 44(1): 5158. PMid:12515838 http://dx.doi.org/10.1176/appi.psy. 44.1 .51

[14] Sukati N, Mndebele S, Makoa E, et al. HIV/AIDS Symptom Management in South Africa. Journal of Pain and Symptom Management. 2005; 29: 185-192. PMid:15733810 http://dx.doi.org/10.10 16/j.jpainsymman. 2004.05.007

[15] Abboud S, Noureddine S, Huijer H, et al. Quality of life in people living with HIV/AIDS in Lebanon. AIDS Care. 2010; 22(6): 687-696. PMid:20461571 http://dx.doi.org/10.1080/09540 120903334658

[16] Phalade N, Human S, Dlamini S, et al. Quality of life and the Concept of "Living Well" with HIV/AIDS in Sub-Saharan Africa. Journal of Nursing Scholarship. 2005; 37(2): 120-126. http://dx.doi.org /10.1111/j.1547-5069.2005.00023.x

[17] World Health Organization Quality of life Group. The World Health Organization Quality of life Assessment: Position paper from the World Health Organization. Social Science and Medicine. 1995; 41(10): 1403-1409. http://dx.doi.org/10.1016/0277-953 6 (95) $00112-\mathrm{K}$

[18] Lorenz K, Shapiro M, Asch S, et al. Associations of symptoms and health-related quality of life: Findings from a national study of persons with HIV infection. Annals of Internal Medicine. 2001; 134(9): 854-860. http://dx.doi.org/10.7326/0003-4819-1 34-9_Part_2-200105011-00009

[19] Tangkawanich T, Yunibhand J, Thanasilp S, et al. Causal model of health: Health-related quality of life in people living with HIV/AIDS in northern region of Thailand. Nursing and Health Sciences. 2009; 10: 216-221. PMid:18786064 http://dx.doi.org/10.1111/j $.1442-2018.2008 .00400 . \mathrm{x}$

[20] Demmer C. Quality of life and risk perception among predominantly heterosexual, minority individuals with HIV/AIDS. Aids Patient Care and STDs. 2001; 15(9): 481-489. PMid:11587634 http://dx.doi.org/10.1089/108729101753145475 
[21] Ware JE, Kosinski M, Dewey J, et al. How to Score and Interpret Single-Item Health Status Measures: A Manual for Users of the SF-8 Health Survey. Boston, Massachusetts, QualityMetric. 2001.

[22] Abera K, Gedif T, Engidawork E, et al. Quality of life of people living with HIV/AIDS and on highly active antiretroviral therapy in Ethiopia". African Journal of AIDS Research. 2010; 9(1): 31-40. PMid:25860411 http://dx.doi .org/10.2989/1608590 6.2010 .484560

[23] Omisakin FD. Developing, Testing and Refining of a Model for Implementation of HIV/AIDS Self-Management Education In A Semi-Rural Area In Kwazulu-Natal, South Africa, Doctoral Thesis, University of KwaZulu-Natal, South Africa. 2011.

[24] Lorig K, Sobel D, Ritter P, et al. Effect of a selfmanagement program on patients with chronic disease. Effective Clinical Practice. 2001; 4:
256-262. PMid:11769298

[25] Omisakin FD. A Qualitative Study of Self-Management Needs of People Living with HIV/AIDS in a Semi-rural Area in KwaZuluNatal South Africa. West African Journal of Nursing. 2014; 25(1): 84-95.

[26] Skevington S, Norweg S, Standage M, et al. Predicting quality of life for people living with HIV: international evidence from seven cultures. AIDS Care. 2010; 22: 614-622. PMid:20229378 http://dx.doi.org/10.1080/09540120903311466

[27] Postard V, Chasany O, Lavignon M, et al. Better health-related quality of life after switching from a virologically effective regimen to a regimen containing efavirenz or nevirapine. AIDS Care. 2010; 22 54-61. PMid:20390481 http://dx.doi.org/10.1080/0954012 0903033250 